\title{
Body composition, dietary intake and supplement use among triathletes residing in the Western Cape
}

\author{
Sunita Potgieter (Master of Nutrition) ${ }^{1}$ \\ Demetre Labadarios (PhD Nutrition, MB ChB) ${ }^{2}$ \\ Irene Labuschagne (BSc Dietetics) ${ }^{1}$ \\ ${ }^{1}$ Department of Interdisciplinary Health Sciences, Division Human Nutrition, Stellenbosch University \\ ${ }^{2}$ Population Health, Health Systems and Innovation, Human Sciences Research Council, \\ Cape Town
}

Correspondence to: Sunita Potgieter (sunita@sun.ac.za)

\begin{abstract}
Objective. The aim of this study was to determine body composition, dietary intake and supplement use among Olympic and Ironman distance triathletes residing in the Western Cape.

Methods. A descriptive, analytical, cross-sectional study design was conducted in Western Cape Province. Twenty-six triathletes registered with Triathlon South Africa were included. Percentage body fat was measured via multi-frequency bio-electrical impedance analysis and anthropometry. Dietary intake and supplement use were measured with an estimated 3-day food record and questionnaire.

Results. The mean age of the men and women was $38 \pm 7$ and $38 \pm 10$ years respectively. The mean amount of training per week for men and women respectively was $15 \pm 4$ and $15 \pm 5$ hours. The percentage body fat (\%BF) of men and women was $13 \pm 4 \%$ and $21 \pm 6 \%$, respectively. The mean dietary macronutrient intake for men and women respectively was for total energy intake $14535 \pm 4510 \mathrm{~kJ}$ and $9004 \pm 2369 \mathrm{~kJ}$, carbohydrate intake $5.3 \pm 1.9 \mathrm{~g} / \mathrm{kg}$ and $3.5 \pm 1.0 \mathrm{~g} / \mathrm{kg}$, protein intake $2.0 \pm 0.5 \mathrm{~g} / \mathrm{kg}$ and $1.2 \pm 0.2 \mathrm{~g} / \mathrm{kg}$ and fat intake $35 \pm 10 \%$ and $30 \pm 6 \%$ of total energy intake. Seventy-three per cent of the triathletes used over-thecounter dietary supplements.

Conclusion. Percentage body fat of the men and women was at the upper end of the range associated with elite athletes. Overall the athletes had a fairly good intake of macro- and micronutrients. Inadequate habitual carbohydrate intake was attenuated by the vast majority of the triathletes taking additional carbohydrate supplementation. Various supplements were used widely among the athletes.
\end{abstract}

\section{Introduction}

Body composition is a very important aspect of an athlete's performance. According to the American Dietetic Association: 'body weight can influence an athlete's speed, endurance and power, whereas body composition can affect an athlete's strength, agility and appearance.' Determining optimal body weight and body composition for each individual according to age, sex, genetics and type of sport definitely has been shown to correlate well with race time and increased exercise performance. ${ }^{2}$
Assessment of body composition can be done via various ways. Prediction equations with the use of a combination of anthropometric measurements and bioelectrical impedance analysis measurements have been compared and validated with the criterion methods. ${ }^{3,4}$

Nutrition is known to play a key role in exercise performance and endurance during extensive periods of exercise. In all sport, the main goal of nutritional strategies is to target and eliminate factors that impair exercise performance; these factors include fatigue, thirst, muscle glycogen depletion and gastro-intestinal disturbances. ${ }^{5}$

Nutrition is an important modifiable factor towards achieving the optimal body composition as well as providing fuel for increased levels of training. Adequate energy should come from a wide variety of available foods which provide carbohydrate, protein, fat and micronutrients. ${ }^{1}$ Marginal vitamin and mineral deficiencies have been found to be present in some elite athletes, due to either an inadequate diet, reduced absorption by the gastro-intestinal tract, increased excretion in sweat, urine and faeces, increased turnover and the consequent biochemical adaptation to physical activity. ${ }^{6}$ Most athletes believe that supplements are necessary in order for an endurance athlete to reach their increased nutritional requirements. They also believe that supplements can promote changes due to activity, provide more consistent training sessions, improve recovery of muscle tissue between sessions, reduce the prevalence of injury or infection and enhance their competitive performance. ${ }^{7}$ A triathlete has to ensure that his/her dietary intake, including the use of supplements, body composition and general immune health, are in harmony, not only for groups of athletes, but also specifically tailor made for the individual according to age, gender, ethnicity and genetics. In Southern Africa, to our knowledge, no study has investigated these aspects in triathletes competing in Olympic and Ironman distance events; therefore, the main aim of this study was to determine the body composition, dietary intake and supplement use amongst triathletes residing in the Western Cape region. A secondary aim was to determine and compare percentage body fat measured via anthropometry and multi-frequency bioelectrical impedance analysis.

\section{Methods}

The study design was descriptive and cross-sectional with an analytical component. A convenient sample was selected from both the 
TABLE 1. Mean (SD) demographic and training characteristics of the triathletes by gender

\begin{tabular}{|c|c|c|c|}
\hline Athletes characteristics & $\begin{array}{l}\text { Male } \\
\text { Mean } \pm \text { SD } \\
(N=13)\end{array}$ & $\begin{array}{l}\text { Female } \\
\text { Mean } \pm S D \\
(N=13)\end{array}$ & t-test; $p$-value \\
\hline \multicolumn{4}{|c|}{ Demographic characteristics } \\
\hline Age (years) & $37.9 \pm 6.8$ & $37.5 \pm 9.6$ & $\mathrm{t}=0.1 ; p=0.050$ \\
\hline \multicolumn{4}{|c|}{ Anthropometric characteristics } \\
\hline Height (m) & $1.8 \pm 0.1$ & $1.7 \pm 0.1$ & $\mathrm{t}=3.9 ; p=0.001$ \\
\hline Body weight $(\mathrm{kg})$ & $78.9 \pm 12.9$ & $63.9 \pm 10.3$ & $\mathrm{t}=3.3 ; p=0.003$ \\
\hline Body mass index $\left(\mathrm{kg} / \mathrm{m}^{2}\right)$ & $24.5 \pm 3.2$ & $22.6 \pm 2.8$ & $\mathrm{t}=1.6 ; p=0.100$ \\
\hline \multicolumn{4}{|c|}{ Training characteristics $(N=12)^{*}$} \\
\hline Total hours training per week & $15.1 \pm 4.1$ & $15.3 \pm 4.7$ & $\mathrm{t}=-0.1 ; p=0.900$ \\
\hline Swimming (hours per week) & $3.5 \pm 2.1$ & $4.2 \pm 2.5$ & $\mathrm{t}=-0.7 ; p=0.500$ \\
\hline Bicycling (hours per week) & $6.5 \pm 2.1$ & $6.4 \pm 2.5$ & $\mathrm{t}=0.1 ; p=0.900$ \\
\hline Running (hours per week) & $4.2 \pm 2.4$ & $4.3 \pm 1.7$ & $\mathrm{t}=-0.1 ; p=0.900$ \\
\hline \multicolumn{3}{|l|}{ (hours per week) } & $\mathrm{t}=1.1 ; p=0.300$ \\
\hline Swimming (km per week) & $6.4 \pm 2.6$ & $10.2 \pm 5.9$ & $\mathrm{t}=2.1 ; p=0.010$ \\
\hline Bicycling (km per week) & $173.8 \pm 8.1$ & $188.9 \pm 88.5$ & $\mathrm{t}=0.5 ; p=0.600$ \\
\hline Running (km per week) & $39.6 \pm 17.9$ & $41.5 \pm 16.6$ & $\mathrm{t}=-0.3 ; p=0.800$ \\
\hline
\end{tabular}

2007 and 2008 Western Province Triathlon (WPTA) team. Twentysix of these 91 (29\% response rate) athletes were recruited by sending out an e-mail to all registered triathletes using the WPTA database and the placement of an advertisement on the WPTA website (http://www.wptriathlon.org). A reminder notice to participation was sent out midway during data collection to achieve maximum possible voluntary participation. The investigator also distributed pamphlets at most of the triathlon races during the 2007/2008 season. Male or female triathletes aged $18-70$ years, triathletes on the WPTA team of 2007 and 2008 and who were training more than 10 hours per week (swimming, cycling and running) or triathletes who completed an Ironman distance event 6 months prior to data collection and training more than 10 hours per week were included. The data collection phase was during the South African Triathlon season from June 2007 to March 2008.

The height and weight of the subjects were measured using a Seca 767 Column Scale with height meter according to specifications from the literature. ${ }^{8}$ The bicep, tricep, sub-scapular, supra-iliac, abdominal, chest, mid-axilla, thigh and calf skinfold thickness were measured with a Dial Gauge Harpenden Skinfold Caliper. Three skinfold measurements were taken at each individual site and the mean calculated for use in data analysis. All the anatomical sites were found as indicated for each individual skinfold thickness according to standard protocol. ${ }^{8}$ Body composition of the subjects was measured using a Bodystat Quadscan $4000 \mathrm{SN}(5 \mathrm{kHz}, 50 \mathrm{kHz}$, $100 \mathrm{kHz}$ and $200 \mathrm{kHz}$ ) Isle of Mann, 2000 multi-frequency bioelectrical impedance (MF-BIA) meter. Subjects were asked to adhere to the pretest conditions before BIA measurement was taken. Subjects were asked to remove all jewellery, watches and belts and instructed to remove the right shoe and sock as well as clear the hand and wrist area. Subjects had fasted for $3-4$ hours and abstained from exercising for 12 hours prior to the measurement. They were asked not to consume any alcohol or caffeine for 24 hours prior to the measurement. Subjects were asked to lie in the supine position on

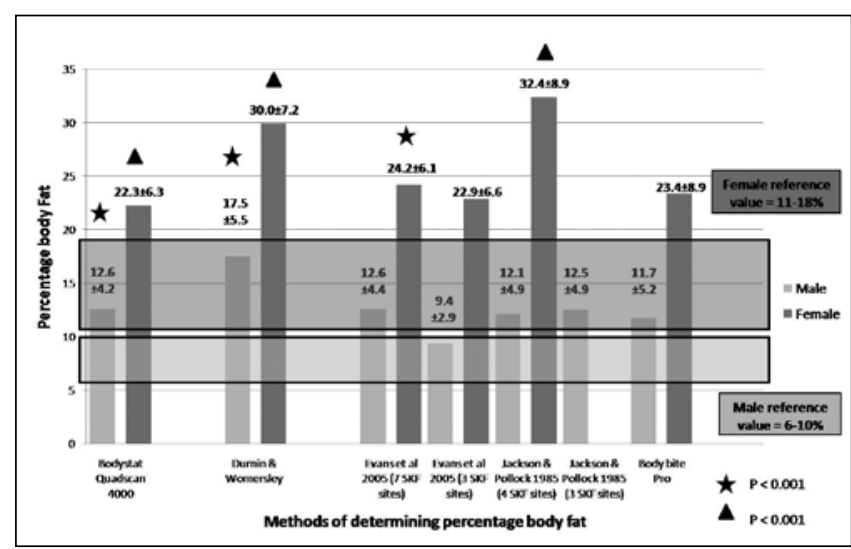

Fig. 1. Mean (SD) of percentage body fat of triathletes by gender (male $\mathrm{N}=12$, female $\mathrm{N}=9$ ); prediction equations could not be determined from subjects due to SKF measurements not obtained from subjects due to variation in skin compressibility and an increased muscle mass, making the skinfold thickness difficult and inaccurate to measure.

a plinth for approximately 5 minutes before the measurements were taken. All the measurements were taken inside a building at normal room temperature and calibration and placement of the electrodes were as described by the manufacturer in the instruction manual.

Dietary intake was measured using a 3-day estimated food record. The food record also contained a section where the subjects were instructed to record daily supplement use. The subjects were asked to write down their food and beverage intake as accurately as possible and they signed a declaration stating that the information given was an accurate reflection of their dietary intake. They were instructed to record two weekdays and one weekend day on the food record. They were also asked to record their training on the days the food record was kept. An additional questionnaire was completed 


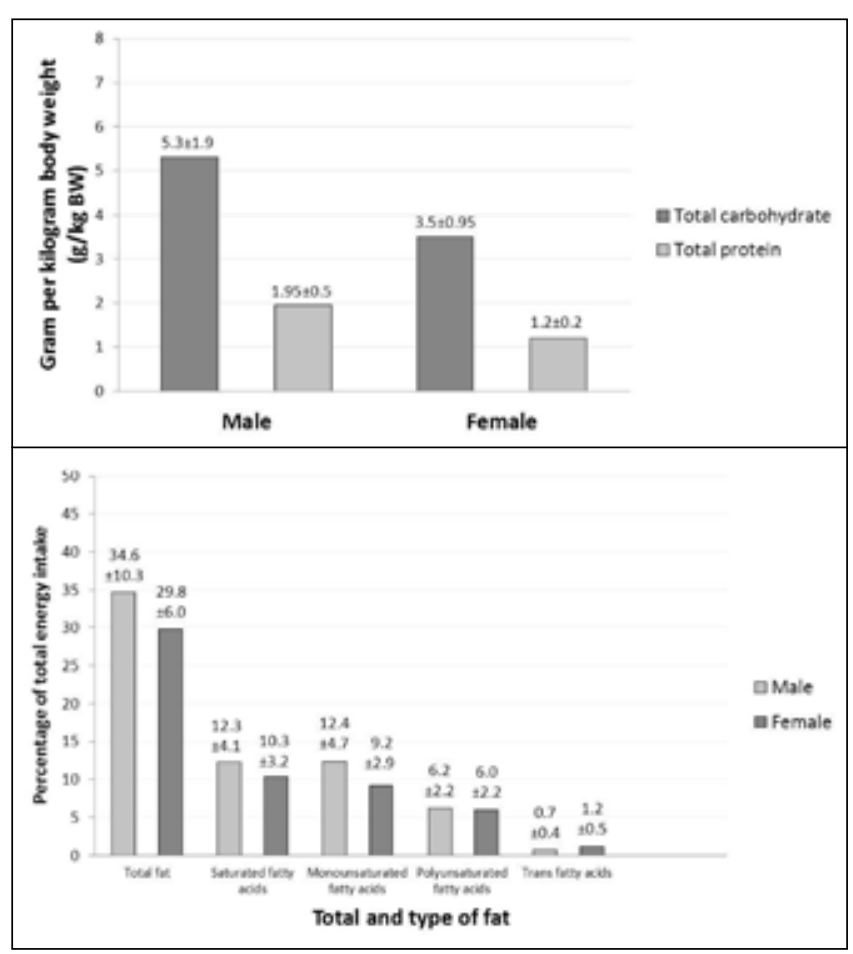

Fig. 2. Mean (SD) of carbohydrate and protein intake of triathletes by gender $(\mathrm{N}=18)^{*}$ (top) and mean (SD) of fat intake of triathletes by gender $(\mathrm{N}=18)^{*}$ (bottom). ${ }^{*}$ Only 9 females and 9 males were included in the analysis of dietary intake because only 18 of the 26 subjects returned their completed food record. Recommended protein intake is $1.2-1.7 \mathrm{~g} / \mathrm{kg}$ body weight/day, recommended carbohydrate intake is 6 - $8 \mathrm{~g} / \mathrm{kg}$ body weight/day, recommended fat intake (percentage of total energy) is $25 \%$, SFA $=10 \%$, MUFA $=10 \%$, PUFA $=10 \%$, TFA $<2 \%$ of TE.

by the subjects indicating general supplement use and reasons for taking the supplements as well as their general training regimen.

All triathletes gave informed written consent and the study was approved by the Health Research Ethics Committee of Stellenbosch University (Reference number: N07/03/07).

\section{Data analysis}

A registered dietitian edited and analysed the dietary intake data using the Food Finder III computer software program (http://www. wamsys.co.za) and prediction equations were used to calculate percentage body fat from anthropometrical measurements. ${ }^{9-12}$

\section{Statistical analysis}

Data were entered into a spreadsheet on Microsoft Excel and transferred to Statistica 8.0 for statistical analysis in consultation with a statistician. Due to the descriptive and informative nature of the study, mostly descriptive statistics in the form of mean and standard deviation (SD) for nominal data and percentages of the total population for ordinal data were calculated to determine the central tendency. When repeated measures were compared with one another, repeated measures analysis of variance (ANOVA) was used. The technique of bootstrapping was applied to estimate sample distributions for data from a bivariate normal distribution and the post hoc Bonferroni test was applied to determine the significant differences between group means during analysis of variance $(p<0.01)$.

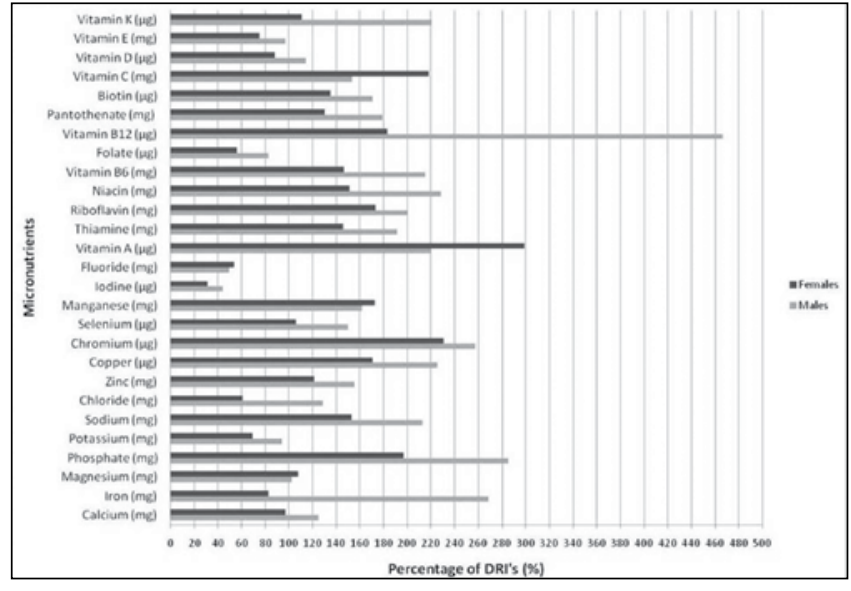

Fig. 3. Mean (SD) of micronutrient intake expressed as a percentage of the dietary reference intakes (DRIs) of the triathletes by gender. Due to the limited reference values available for the interpretation of micronutrient intake in groups, the recommended daily allowance (RDA) values were used. Where available the adequate intake $(A I)$ and the estimated average requirement (EAR) values were used.

\section{Results}

Twenty-six triathletes were included of whom 13 were male and 13 female. All the athletes were Caucasian, except for one male participant who was of mixed ancestry. The demographic and training characteristics of the triathletes are summarised in Table I.

\section{Body composition}

The different \%BF values for men and women respectively differed significantly irrespective of the method used and are portrayed against gender-specific reference values in Fig. 1.

When comparing the measurements, no significant difference was found with the men's results when using analysis of variance and applying the Bonferroni correction between the \%BF from the MF-BIA (12.6 \pm 4.2$), \% B F$ from the equation using $7 \mathrm{SKF}$ sites from Evans et al. $2005^{9}(12.6 \pm 4.4)(p=1.00)$, the $\% \mathrm{BF}$ from the $4 \mathrm{SKF}$ site equation from Jackson and Pollock $1985^{10}(12.1 \pm 4.9)(p=1.00)$, the \%BF from the $3 \mathrm{SKF}$ site equation from Jackson and Pollock $1985^{10}(12.5 \pm 4.9)(p=1.00)$ and the \%BF from the Body Bite nutrition software program ${ }^{11}(11.7 \pm 5.2)(p=1.00)$. A significant difference was found between \%BF measured from MF-BIA and the 4 SKF site equation from Durnin and Womersley ${ }^{12}(17.5 \pm 5.5)(p<0.05)$ and the $\% \mathrm{BF}$ from the $3 \mathrm{SKF}$ site equation from Evans et al. $2005^{9}(9.4 \pm 2.9)$ $(p=0.01)$.

The \%BF from the women's results showed no significant differences in the \%BF from MF-BIA $(22.3 \pm 6.3)$ and the \%BF from the $7 \mathrm{SKF}$ site equation from Evans et al. $2005^{9}(24.2 \pm 6.1)$ $(p=1.00)$, the \%BF from the $3 \mathrm{SKF}$ site equation from Evans et al. $2005^{9}(22.9 \pm 6.6)(p=1.00)$ and the \%BF from the Body bite nutrition software program ${ }^{11}(23.4 \pm 9.0) \quad(p=1.00)$. There was however a statistically significant difference between the \%BF from MF-BIA and the \%BF from the $4 \mathrm{SKF}$ site equation from Durnin and Womersley ${ }^{12}$ $(30.0 \pm 7.2)(p<0.05)$ and the 4 SKF site equation from Jackson and Pollock $1985^{10}(32.40 \pm 8.95)(p<0.05)$.

\section{Dietary intake and supplement use}

The total number of completed food records received was 18 out of a possible 26 food records ( $69 \%$ response rate), of which 9 were 
TABLE II. Prevalence of supplement use among the triathletes

\begin{tabular}{|c|c|c|c|}
\hline Supplement category & Supplements & Percentage triathletes $(N=26)$ & $\begin{array}{l}\text { Chi-square; } \\
p \text {-value }\end{array}$ \\
\hline \multirow[t]{2}{*}{ Increased muscle growth and repair } & Protein & $100 \%(N=26)$ & No value \\
\hline & Amino acids & $27 \% \quad(N=7)$ & $p=0.7$ \\
\hline \multirow[t]{2}{*}{ Increased energy supply } & Carbohydrate & $81 \% \quad(N=21)$ & $p=0.1$ \\
\hline & Creatine & $12 \% \quad(N=3)$ & $p=0.5$ \\
\hline \multirow[t]{2}{*}{ Increased immune function } & Antioxidants & $54 \% \quad(N=14)$ & $p=1.0$ \\
\hline & Glutamine & $4 \% \quad(N=1)$ & $p=0.3$ \\
\hline Increased joint health & Glucosamine sulphate & $4 \% \quad(N=1)$ & $p=0.3$ \\
\hline CNS stimulants & Caffeine & $4 \% \quad(N=1)$ & $p=0.3$ \\
\hline Fat reduction & Carnitine & $4 \% \quad(N=1)$ & $p=0.3$ \\
\hline Electrolytes & Salt tablets & $19 \% \quad(N=5)$ & $p=0.6$ \\
\hline \multirow[t]{9}{*}{ General health } & Multivitamin and mineral & $81 \% \quad(N=21)$ & $p=0.6$ \\
\hline & Vitamin $B_{12}$ & $65 \% \quad(N=17)$ & $p=0.7$ \\
\hline & Single minerals & $58 \% \quad(N=15)$ & $p=0.7$ \\
\hline & Iron & $4 \% \quad(N=1)$ & $p=0.3$ \\
\hline & Calcium & $4 \% \quad(N=1)$ & $p=0.3$ \\
\hline & Magnesium & $27 \% \quad(N=7)$ & $p=0.2$ \\
\hline & Essential fatty acids & $8 \% \quad(N=2)$ & $p=1.0$ \\
\hline & Herbal supplements ${ }^{*}$ & $42 \% \quad(N=11)$ & $p=0.7$ \\
\hline & Probiotics & $4 \% \quad(N=1)$ & $p=0.3$ \\
\hline
\end{tabular}

males and 9 females. The food records were handed out and the subjects were given a pre-paid postage envelope to mail it back to the researcher. However, not all the subjects sent the completed food records back or responded to follow-up reminders.

Dietary intake from diet does not include intake from additional supplements. This approach was adopted because it proved impractical to quantify the amounts consumed from the supplements used correctly. The total energy intake of the athletes for men and women respectively were $14535 \pm 4510 \mathrm{~kJ}$ and $9004 \pm 369 \mathrm{~kJ}$. Upon calculating energy availability, the men and women had a mean energy availability of $162 \pm 58 \mathrm{~kJ} / \mathrm{kg}$ fat free mass (FFM) and $144 \pm 56 \mathrm{~kJ} / \mathrm{kg} /$ FFM respectively. The results from the men and women differed significantly $(\mathrm{t}=3.3 ; p=0.05)$. The macronutrient intake is summarised in Fig. 2.

The intake of most of the micronutrients fell within $67-133 \%$ of the dietary reference intakes (DRIs). ${ }^{13}$ The micronutrients with an intake below $67 \%$ of the DRIs for men included iodine $44 \%$ and fluoride $49 \%$ and for women, chloride $61 \%$, iodine $31 \%$ and fluoride $52 \%$. Most of the micronutrients from dietary intake alone above $133 \%$ of the DRI were still below the tolerable upper limit and not too excessive. The men's intake of sodium, manganese and niacin was above the upper limit at $213 \%, 162 \%$ and $228 \%$ of the DRI respectively. Only the manganese intake of the women, $174 \%$ of the DRIs, fell above the upper limit. The micronutrients expressed as a percentage of the DRIs are shown in Fig. 3.

Provision has been made in the Food Finder database for 145 nutrients. Information is not yet available on all the nutrients. There may be a significant number of missing values for nutrients and micronutrient intake should be interpreted keeping in mind the limitations of the database.
A separate questionnaire was given to the subjects to report supplement and reasons for supplement use $(N=26)$. Seventy-three per cent $(N=19)$ of the triathletes used over-the-counter dietary supplements (chi-square; $p=1.0$ ). Supplement use is summarised in Table II. The athletes took supplements daily $(35 \%)(N=9)$ several times a week $(19 \%)(N=5)$ or during specific times, i.e. increased training or racing on consecutive weekends $(19 \%)(N=5)$. Reasons why the triathletes were taking the supplements are summarised in Fig. 4.

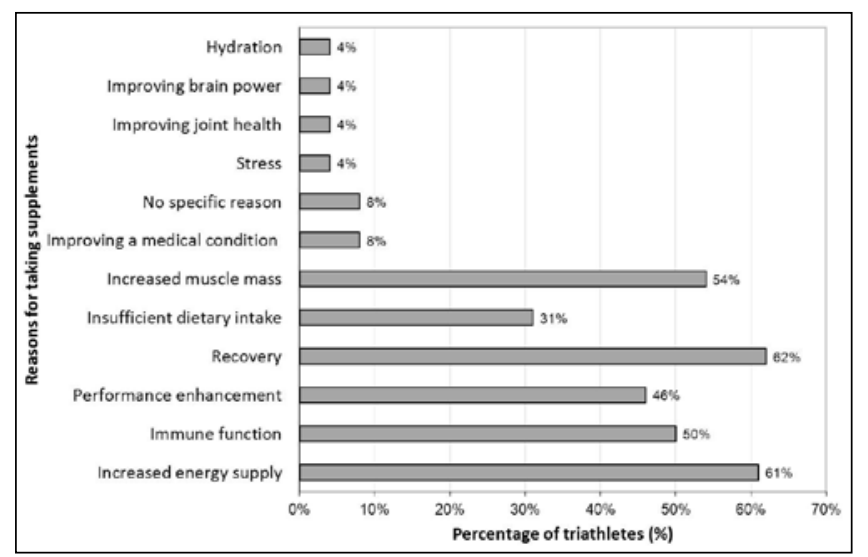

Fig. 4. Reasons given by triathletes for taking supplements.

\section{Discussion}

This is the first study of its type in South Africa using triathletes as study population. The findings of this study contribute to the body of current knowledge on endurance athletes like runners and cyclists, 
but gives new insight on the nutritional status of triathletes. The key findings of the present study were that percentage body fat calculated from skinfold prediction equations generally correlated well with percentage body fat measured with MF-BIA. The percentage body fat of the men and women was at the upper end of the range associated with elite athletes and related more to the percentage body fat of amateur athletes. The athletes had a good dietary intake of micronutrients. The triathletes consumed less than optimal amounts of dietary carbohydrate and supplements were used widely, including carbohydrate and protein supplementation even though dietary protein intake was adequate for both men and women. Fat intake was higher than the recommendation in both groups.

\section{Body composition}

Percentage body fat calculated from skinfold prediction equations generally correlated well with percentage body fat measured with MF-BIA. Significant associations in both and men women were obtained between percentage body fat calculated from skinfold measurements and MF-BIA. The findings of this study support those described by Ostojic et al. 2005, who found that \%BF from skinfold measurements and \%BF from BIA correlated well in male athletes. ${ }^{14}$

\section{Dietary intake and supplement use}

An athlete's habitual dietary intake is very important to ensure that he or she meets the increased energy requirements of triathlon. The body's ability to adapt to the stress of intense daily exercise depends on the adequacy of the athlete's diet. ${ }^{15}$ The World Health Organization defines energy requirement as 'the level of energy intake from food that will balance energy expenditure when the individual has a body size and composition, and level of physical activity, consistent with long-term good health; and that will allow for the maintenance of economically necessary and socially desirable physical activity. ${ }^{16}$ The International Olympic Committee (IOC) recommends in its position statement on nutrition for athletes that energy availability, rather than total energy requirements, should be calculated $(135 \mathrm{~kJ} / \mathrm{kg} /$ FFM). ${ }^{17}$ They concluded that if energy availability is below the recommendation, that there can be changes in metabolic and hormonal function, which can affect sport performance and health in general. This is especially true for females where a reduced energy availability can influence reproductive health. ${ }^{17}$ The male and female athletes in the present study had a higher than recommended energy availability. The women also had a higher than anticipated percentage body fat and a normal body mass index (BMI) and none of the women reported weight loss in the preceding months, which indicates that the women are indeed in energy balance. The majority of the women also reported having regular monthly menses $(77 \%)$. The women's results for total energy intake also coincided with findings of Worme et al. (1990), ${ }^{18}$ who found the mean total energy intake of 21 recreational female triathletes to be $9058 \mathrm{~kJ}$. They also reported the mean total energy intake for 50 male triathletes to be $11591 \mathrm{~kJ}^{18}$

The evidence on importance of adequate carbohydrate intake for athletes has been described and concludes that muscle glycogen is the most important energy substrate during endurance exercise and a decreased intake can lead to less than optimal training, recovery post training and performance. A sub-optimal carbohydrate intake can also lead to feeling fatigued, often not being able to finish training sessions due to a feeling of hitting the wall, lack of energy, heavy legs, slow rate of recovery, and loss of concentration, dizziness, irritability and fainting. ${ }^{19}$ The carbohydrate intake of 21 female and 50 male recreational triathletes as reported by Worme et al. was $5.1 \mathrm{~g} / \mathrm{kg}$ body weight and $4.9 \mathrm{~g} / \mathrm{kg}$ body weight for men and women respectively. ${ }^{18}$ Nogueira et al. (2004) also described the $\mathrm{CHO}$ intake of endurance athletes as $4.5-11.3 \mathrm{~g} / \mathrm{kg} \mathrm{BW}$ for males and $4.4-7.2$ $\mathrm{g} / \mathrm{kg}$ BW for females. ${ }^{20}$ Frentsos et al. (1997) also reported that 6 elite triathletes only had a carbohydrate intake of $4 \mathrm{~g} / \mathrm{kg} \mathrm{BW}$ before intervention. ${ }^{21}$ The male triathletes in the present study are meeting carbohydrate requirements and the female athletes are not meeting the recommended requirements, with an intake of $5.26 \mathrm{~g} / \mathrm{kg} \mathrm{BW}$ for men and $3.54 \mathrm{~g} / \mathrm{kg} \mathrm{BW}$ for women, respectively. Literature suggests that endurance athletes should have a carbohydrate intake of $5-7 \mathrm{~g} /$ $\mathrm{kg} \mathrm{BW}$ or $6-8 \mathrm{~g} / \mathrm{kg} \mathrm{BW} .^{17,22}$ However, the practical implementation of this recommendation should be taken into consideration, especially with the female athletes in the present study who have a higher than recommended percentage body fat and adequate energy availability. Most $(81 \%)$ of the triathletes in our study group also consumed some form of a $\mathrm{CHO}$ supplementation and listed an increase in energy supply as one of the main reasons for taking supplements. This could make up for the inadequate dietary $\mathrm{CHO}$ intake; however quantifying the amount of $\mathrm{CHO}$ supplements taken in future studies is recommended.

The present study indicated that the dietary intake of protein for male triathletes was $1.95 \mathrm{~g} / \mathrm{kg} \mathrm{BW}$ and for female triathletes $1.20 \mathrm{~g} /$ $\mathrm{kg} \mathrm{BW}$. Worme et al. reported the habitual protein intake of both male and female triathletes to be $1.4 \mathrm{~g} / \mathrm{kg}$ body weight per day. ${ }^{18}$ Nogueira et al. reported a habitual dietary protein intake for endurance athletes as $1.2-2.0 \mathrm{~g} / \mathrm{kg}$ body weight. ${ }^{20}$ Protein in combination with carbohydrate in an endurance athlete's diet is especially important for recovery after training sessions and when carbohydrate intake after training is limited, such as a low appetite or short recovery periods. It is required to cover the increased losses of amino acids oxidised during exercise and to provide extra raw material to replace exercise-induced muscle damage. ${ }^{23}$ The requirements for protein in endurance athletes are higher than those of sedentary peers (1.2 $1.7 \mathrm{~g} / \mathrm{kg}$ body weight v. $0.8-1.0 \mathrm{~g} / \mathrm{kg}$ body weight) ${ }^{22}$ due to the fact that some amino acids (including the branched chain amino acids) are oxidised in larger amounts during exercise. ${ }^{23}$ All of the athletes in the present study also reported taking some form of protein supplementation, which is unnecessary as well as energy dense and can lead to weight gain.

Fat is a very important macronutrient for endurance athletes as it provides the training diet with essential fatty acids (EFAs) and fat-soluble vitamins. The male $(35 \pm 10 \%)$ and female $(30 \pm 6.0 \%)$ triathletes in this study had a very high fat intake compared with the requirements of $25 \%$ of total energy intake. ${ }^{1}$ The distribution of the different types of fatty acids in this group was not according to prudent dietary guidelines and recommendations to increase sources of poly- and monounsaturated fatty acids while reducing saturated and total fat intake in the diet should be made.

There are certain vitamin and mineral requirements that are increased during physical activity and according to the $\mathrm{IOC}$, adequate intakes of iron, copper, manganese, magnesium, selenium, sodium, zinc, vitamin $A, E_{17} C, B_{6}$ and $B_{12}$ necessary for optimal health and performance. ${ }^{17}$ It should be noted that supplementation of micronutrients are not required and that it only affects performance if the athlete has a deficiency of the nutrient. ${ }^{7}$ In the present study, the athletes had a good intake of micronutrients and most values fell within $67-133 \%$ of the DRIs. Micronutrients of which the intake was below $67 \%$, such as iodine and fluoride, are not a concern as the athletes will take this in via iodated salt and toothpaste, which is not accounted for in the dietary analysis software programme. The micronutrient intake that fell above the $133 \%$ of the DRI is still below the tolerable upper level and not a concern. In a study by Striegel et al. $(2006)^{24}$ on Master's athletes, $61 \%$ of athletes were consuming 
dietary supplements as compared with our study group in which $73 \%$ took dietary supplements. The majority of the triathletes took a form of multivitamin supplementation which shows that they feel their diet is not providing adequate nutrition. They also indicated an inadequate diet or nutrient replacement as being a popular reason for using supplements. Other popular reasons for taking supplements included to provide an increased energy supply, optimise recovery, increase lean body mass and to support the immune function. According to the $\mathrm{IOC}$, an athlete can take a multivitamin-mineral preparation to support a low energy or restricted diet, although in our study population this does not seem necessary. ${ }^{17}$

Supplement use in athletes should be carefully monitored. Contamination of supplements and ingredients in supplements with no beneficial effect can harm athletes and the IOC has clear guidelines as to which supplements are recommended and which are banned. $^{25}$

\section{Conclusion}

In the present study we found that two of the popular field methods for determining percentage body fat in athletes do correlate well when the appropriate equations are used. Our dietary intake findings were that the triathletes had a high energy availability and consumed enough dietary carbohydrate and protein. The fat intake was higher than the recommendation in both groups. Supplements were also widely used among the athletes. Recommendations for future studies would be to include a larger study population as it would be beneficial to have a large enough study population to divide the group into subgroups of elite and amateur athletes. Future studies can also go into more depth regarding quantifying the supplements used by the athletes and adding this to determine their habitual dietary intake. Timing of nutrient intake in relation to training would also provide valuable information in future studies.

\section{References}

1. American Dietetic Association. Position of the American Dietetic Association Dietitians of Canada and the American College of Sport: Nutrition and Athletic performance. J Am Diet Assoc 2009;109:509-527.

2. Knechtle B, Wirth A, Baumann B, Knechtle $P$, Rosemann $T$ and Senn $O$. Differential correlations between anthropometry, training volume, and performance in male and female Ironman athletes. J Strength Cond Res 2010;24(10):2785-2793.
3. Garcia AL, Wagner K, Hothorn T, Koebnick C, Joachim H, Zunfit F, Trippo $\mathrm{U}$. Improved prediction of body fat by measuring skinfold thickness, circumferences, and bone breadths. Obesity Research 2005;13(3):626-634.

4. Kyle UG, Bosaeus I, De Lorenzo AD, Deurenberg P, Elia M, Gomez JM et al. Bioelectrical Impedance Analysis - part 1: Review of principles and methods. Clin Nutr. 2004;23:1226-1243.

5. Bentley D, Cox G, Green D, Laursen P. Maximising performance in triathlon: Applied physiological and nutritional aspects of elite and non-elite competitions. J Sci Med Sport 2008;11(4):407-417.

6. Knez W, Peake J. The prevalence of vitamin supplementation in ultraendurance triathletes. Int J Sport Nutr Ex Met 2010;20(6):507-514.

7. Maughan RJ, Depiesse F, Geyer H. The use of dietary supplements by athletes. J Sport Sci 2007;25(SI):S103-S113.

8. Lee RD, Nieman DC. Nutritional Assessment. 3rd ed. 2003:63-215.

9. Evans EM, Rowe DA, Misic MM, et al. Skinfold prediction equation for athletes developed using a four-component model. Med Sci Sports Exerc 2005;2006-2011.

10. Jackson AS, Pollock M. Practical assessment of body composition. Phys Sport Med 1985; 13:76-90.

11. Body byte ${ }^{\circledR}$ Pro V3.20. Body and Nutrition Manager software program.

12. Durnin JVGA, Womersley J. Body fat assessed from total body density and its estimation from skinfold thickness: measurements on 481 men and women aged from 16-72 years. Br J Nutr 1974;34:77-97.

13. Dietary Reference Intakes. Nutrition Information Centre of the University of Stellenbosch. 2003. Adapted from: Dietary Reference Intakes. The essential guide to nutrient requirements. 2001. Institute of Medicine. Washington: The National Academic Press.

14. Ostojic SM. Estimation of body fat in athletes: Skinfolds vs. bioelectrical impedance. J Sports Med Phys Fitness 2005;46(3):442-446.

15. Laursen PB, Rhodes EC. Factors affecting performance in an ultra-endurance triathlon. Sports Med 2001;31(3):195-209.

16. World Health Organization website [Online] [access 2008, June]; Available: http://www.who.int/bmi/index

17. Burke LM. The IOC consensus on sport nutrition 2003: New guidelines for nutrition for athletes. 2003;13(4):549-52.

18. Worme JD, Doubt TJ, Singh A, et al. Dietary patterns, gastrointestinal complaints, and nutrition knowledge of recreational triathletes. Am J Clin Nutr 1990;51:690-697.

19. Ivy JL. Role of carbohydrate in physical activity. Clin Sports Med. 1999;18(3):469-484

20. Noguiera JA, Da Costa TH. Nutrient intake and eating habits of triathletes on a Brazilian diet. Int J Sport Nutr Exerc Metab 2004;14(6):684-697.

21. Frentsos JA, Baer JT. Increased energy and nutrient intake during training and competition improves elite triathlete's endurance performance. Int $\mathrm{J}$ Sport Nutr 1997;7:61-71.

22. Hawley JA, Burke LM. Peak performance: Training and nutritional strategies for sport. Sydney: Allen and Unwin, 1998.

23. Tipton KD, Wolfe RR. Protein and amino acids for athletes. J Sport Sci 2004;22(1):65-79.

24. Striegel $H$, Simon $P$, Wurster $C$. The use of nutritional supplements among master athletes. Int J Sports Med 2006;27:236-241.

25. The World Anti-doping Code. The 2010 prohibited list International Standard. 2010 [Online] [access 2010, September]; Available:http://www.wadaama.org/Documents/World_Anti-Doping_Program/WADP-Prohibited-list/ WADA_Prohibited_List_2010_EN.pdf. 